\title{
Dental Journal

\section{Perceived parenting style and mother's behavior in maintaining dental health of children with Down syndrome}

\author{
Siti Fitria Ulfah, ${ }^{1}$ Darmawan Setijanto, ${ }^{2}$ and Taufan Bramantoro ${ }^{2}$ \\ ${ }^{1}$ Dental Nursing Program Study, Poltekkes Kemenkes Surabaya, Surabaya - Indonesia \\ ${ }^{2}$ Departement of Dental Public Health, Faculty of Dental Medicine, Universitas Airlangga, \\ Surabaya - Indonesia
}

\begin{abstract}
Background: The number of children with down syndrome in Surabaya has reached 924 children. Prevalence of gingivitis and dental caries (91\% and 93.8\%, respectively) occurs in children with down syndrome aged 6 to 20 years. Oral and dental health problems are found in children with down syndrome because they have physical and motoric limitation in maintaining oral and dental hygiene, thus require parental care from mother. Perceived parenting style includes responsiveness and demandingness. Perceived parenting is crucial for mother whose children have Down syndrome in order to guide their health behavior, particularly to maintain oral and dental health. Purpose: The study aimed to analyze correlation between perceived parenting style and mother's behavior in maintaining dental health of children with Down syndrome. Method: This cross sectional analytical study involved 40 mothers of children aged 7-13 years with Down syndrome enrolled in Special Education Elementary Schools Surabaya and Association of Parents of Children with Down syndrome Surabaya. Data of perceived parenting style (responsiveness and demandingness) and mother's behavior in maintaining dental health were obtained by questionnaire. Composition of each item in questionnaire of perceived parenting style and mother's behavior in maintaining dental health of children with Down syndrome was passed through validity and reliability test. Data analysis was carried out using multiple linear regression correlation test. Result: This present study showed that perceived parenting style is significantly correlated with mother's behavior in maintaining dental health of children with Down syndrome $(R=0.630, p=0.000)$, with perceived parental responsiveness as a strong predictor. Mean score and standard deviation of perceived parental responsiveness and demandingness were $33.00 \pm 2.99$ and $15.55 \pm 1.99$, respectively. Conclusion: Perceived maternal parenting style in children with Down syndrome is closely related to mother's behavior in maintaining dental health of children with Down syndrome.
\end{abstract}

Keywords: perceived parental responsiveness; perceived parental demandingness; dental health maintenance behavior; children with Down syndrome

Correspondence: Taufan Bramantoro, Department of Dental Public Health, Faculty of Dental Medicine, Universitas Airlangga. Jl. Mayjend. Prof. Dr. Moestopo no. 47 Surabaya 60132, Indonesia. E-mail: taufan-b@fkg.unair.ac.id

\section{INTRODUCTION}

Down syndrome or trisomy-21 is congenital disorder characterized by an extra chromosome 21 on the chromosome 21 pair. ${ }^{1}$ This fenotype of triplicate expression is observed on $95 \%$ of trisomy 21 , the remaining $5 \%$ shows a close correlation with other chromosomal disorders. In general, chromosome 21 is related to partial trisomy disorder/anomaly, mosaicism, and translocation. ${ }^{1}$ The number of Down syndrome case in the world remains unknown, but it is estimated up to 8.000 .000 cases. In
Indonesia, the number of people with Down syndrome is about more than $300.000(3.75 \%)$. $^{2}$ According to Statistic Indonesia, the number of children with Down syndrome in Surabaya is about up to 924 children. $^{2}$

People with Down syndrome have different oral health problems compared to general population. ${ }^{3}$ Approximately 96\% of adults with Down syndrome commonly have considerably high prevalence of periodontal disease. ${ }^{4}$ Gingivitis affects $91 \%$ of children aged 6-20 years with Down syndrome. ${ }^{3}$ In Riyadh, children aged 11 years on average with Down syndrome had more gingivitis (46.9\%) 
than control group/normal children (34\%) in all sextants of the mouth except the mandibular middle sextants. ${ }^{5}$ Prevalence of poor oral and dental hygiene in children aged 7 to 12 years with Down syndrome was significantly higher $(87.5 \%)$ than normal children. ${ }^{6}$ Individuals with Down syndrome require assistance from parents and caregivers in order to maintain their daily oral and dental health. ${ }^{7}$

Parents and caregivers usually face oral health care problems in children with Down syndrome. Comprehensively oral health care is indispensable in order to obtain an optimal care. ${ }^{8}$ Mother's perception on children with Down syndrome provides significant impact on their oral and dental hygiene practice. Mother's perception concerning impact of oral and dental health in children with Down syndrome plays an important role in their social contact. ${ }^{9,10}$

Global perceptions of parenting children with Down syndrome were less positive than those of parenting normal children. ${ }^{11}$ Korean mothers of children with Down syndrome experienced two perceived parenting aspects, positive and negative, in raising their children. In addition, mothers of children with Down syndrome in some regions of Korea showed more attention to their children. Mothers tend to be the primary caregivers for children with Down syndrome in Korea. ${ }^{12}$

Parenting children with Down syndrome is considered less favorable and more expensive (i.e, financial, emotional, social) than parenting children with no disabilities. ${ }^{11}$ Perceived parenting style has two dimensions, that are, responsiveness and demandingness. ${ }^{13}$ Parental care of children with Down syndrome is more focused on parental responsiveness. ${ }^{14}$ Responsiveness is the families' ability to respond to the demands and needs of children in an accepting and supportive way by supporting the individuality and assertiveness of the child. ${ }^{14}$

Perceived parental responsiveness is perceived parenting style that includes warmth, open-communication, and care. Warmth is the family's ability to assert the love they feel towards their children sentimentally, emotionally and empathically within the family. ${ }^{15}$ Parental responsiveness is shown through motivation on children in order to support children's development of internalized moral orientation. ${ }^{15}$

In addition to demonstrate parental responsiveness, parents of children with Down syndrome also need to apply parenting style in such discipline, firm, and controlling way. ${ }^{16}$ Parents who give contribution of perception in discipline, firm, and controlling way are called perceived parental demandingness. Perceived parental demandingness is perceived parenting style that highlights monitoring, demandingness, and control of the children's behavior. ${ }^{13}$

Parental care given by parents to their children reflects an behavior, strategy applied by parents themselves to achieve goal in any certain situations. ${ }^{17}$ Parents' behavior in maintaining oral health of children with special needs plays an important role in oral health of their children. ${ }^{18}$ Parents and caregivers particularly mother of children with Down syndrome should guide their children how to practice tooth brushing skill and use of flouride-containing toothpaste to improve oral hygiene of children with Down syndrome. ${ }^{7}$

According to the existing phenomena and supported by study results, we need to analyze the correlation between perceived maternal parenting style and mother's behavior in maintaining dental health of children with Down syndrome in Special Education Elementary Schools Surabaya and Association of Parents of Children with Down syndrome Surabaya

\section{MATERIALS AND METHODS}

This study was observational analytical quantitative study with cross sectional study design which investigates dynamic of correlation between risk factors and effects. This present study involved mothers of children aged 7-13 years with Down syndrome enrolled in Special Education Elementary Schools Surabaya and Association of Parents of Children with Down syndrome Surabaya. Total respondents involved in this study were 40 mothers of children with Down syndrome. Sampling technique was performed as simple random sampling.

Inclusion criteria in this study as follows: 1) mother of children with mild and moderate Down syndrome; 2) mother of children aged 7-13 years with Down syndrome; 3 ) education level of mother of children with Down syndrome is minimum graduated from Senior High School; 4) mothers who are full-time in taking care of their Down syndrome children.

This study used questionnaire as instrument to measure perceived maternal responsiveness and demandingness, and mother's behavior in maintaining dental health of children aged 7-13 years with Down syndrome. Assessment of perceived maternal responsiveness was based on four dimensions included communication, support promotion, expressing affection and harmony in the motherchild relationship. ${ }^{12,13,19}$ Meanwhile assessment of maternal demandingness was based on three dimension included monitoring, demandingness, and control of children's behavior. Assessment of mother's behavior in maintaining dental health of children aged 7-13 years with Down syndrome was based on questionnaire instrument of Chand et $a l .{ }^{20}$ Answers for each statement item about mother's perception of children with Down syndrome shown by options "strongly agree, agree, disagree, strongly disagree". Scoring for each answer option was 4 for strongly agree; 3 for agree; 2 for disagree; and 1 for strongly disagree. Answer options for measurement of mother's behavior were "very often, fairly often, sometimes, and never". Scoring for each answer option was 4 for very often; 3 fairly often; 2 for sometimes; and 1 for never.

Composition of each item in questionnaire of perceived parental responsiveness and demandingness was adopted from perception of parenting questionnaire; ${ }^{13}$ perceived maternal styles $;^{15}$ Malaysian (Sarawak) 
mothers'perspectives; ${ }^{19}$ Maternal perceptions to openended questions about life with Down syndrome in Korea $;{ }^{12}$ parenting a child with Down syndrome $;{ }^{21}$ impact of mothers' oral hygiene knowledge and practice on oral hygiene status of their 12-year-old children. ${ }^{20}$

Before questionnaire instrument passed through realibility and validity test, researcher had involved some experts to compose item of questionnaire, such as public health dentist, pedodontist, and child psychologist. Involvement of these experts aimed to obtain explisitness, sequence of relevance, and comprehensiveness on all items in questionnaire. After all items in questionnaire had been composed, researchers performed validity and reliability test. In those tests, researchers involved 30 mothers of children with Down syndrome to fill out the questionnaire. Those respondents were mothers of children with Down syndrome, members in Association of Parents of Children with Down syndrome Surabaya.

Location of study was at Special Education Elementary Schools Surabaya and Association of Parents of Children with Down syndrome Surabaya. Study period started from May-Juny 2016. This study had been approved by Ethics Committe of Faculty of Dentistry, Airlangga University. The analysis used distribution table which confirmation shown as precentage. ${ }^{22}$ Data analysis in this study used multiple linear regression correlation test (Table 5).

\section{RESULTS}

Results obtained from questionnaire of perceived maternal parenting style in children with Down syndrome consisted of parental responsiveness and demandingness. There were 4 dimensions in perceived parental responsiveness which consisted of 9 items of questionnaire. Whereas perceived parenting demandingness had 3 dimensions which consisted of 5 items of questionnaire.

According to validity and reliability test, cronbach's alpha of perceived parental responsiveness, demandingness, and mother's behavior in maintaining dental health of children with Down syndrome were $0.858,0.754$ and 0.813 , respectively. The result of reliability test showed that each instrument had higher value of cronbach's alpha than critical value for two tailed correlation coefficient with the number of sample as 30 subjects, $r=0.374$.

Assessment of questionnaire items in perceived maternal responsiveness of children with Down syndrome after passed through the reliability and vaidity test consisted of several items, included: "I reassure my child when he/she is afraid, I cheer him/her up when he/she is sad", "I treat him/her as a friend, I pay attention to what he/she should eat and drink", "I pay attention to his/her need of self-care, such as bathing, defecation, urination, and menstruation", "I hug and kiss my child, I am happy when my child could speak a few words that are understandable by anyone", "I spend my strength and time to take care of my child",
"I spend a lot of time to assist my child in learning (for example: speaking, writing, reading, etc)".

Assessment of questionnaire items in perceived maternal demandingness of children with Down syndrome after passed through the reliability and validity test consisted of several items, included: "I threaten my child with scary things when he/she is fussy, stubborn, disobedient, very demanding", "I ignore for a while if he/she keeps on fussy, stubborn, disobedient, very demanding", "I yell loudly when my child keep crying, very demanding". "I watch my child when he/she is in public areas", "I watch my child because I worry about things that could possibly harm him/her".

Assessment of questionnaire items of mother's behavior in maintaining dental health of children with Down syndrome after passed through reliability and validity test consisted of several items, included: "I clean up my child's teeth", "I watch my child when he/she clean up his/her teeth and mouth", "I clean up my child's teeth using toothbrush and toothpaste", "I clean up my child's teeth twice daily", "I clean up my child's teeth only at night before go to bed", "I clean up my child's teeth in the morning after breakfast and at night before go to bed".

In the present study, characteristics of children with Down syndrome and their mothers were presented. Majority of mothers of children with Down syndrome, i.e 26 of them (65\%), aged 40-54 years. Majority of educational level of respondents $(n=30 ; 75 \%)$ was graduated from Senior High School. Employment status of all respondents $(n=40$; $100 \%$ ) was homemaker. Majority of gender of children with Down syndrome was female $(n=23 ; 57.5 \%)$. Ten children with Down syndrome aged 7 years $(n=10 ; 25 \%)$. There were 36 children had moderate level of Down syndrome $(\mathrm{n}=36 ; 90 \%)$.

In subscale of reassuring children when they are afraid, majority of the respondents stated strongly agree $(n=29$; $72.5 \%)$, and only one of them stated strongly disagree $(n=1$; $2.5 \%$ ). In subscale of cheering up the children when they are sad, majority of the respondents stated strongly agree $(n=30 ; 75 \%)$, and only one of them stated strongly disagree $(\mathrm{n}=1 ; 2.5 \%)$. In subscale of treating the children as friend, approximately $70 \%$ or 28 respondents stated strongly agree, and there were still few respondents stated disagree to treat their children as friend. In subscale of paying attention to what their children should eat and drink, approximately $77.5 \%$ or 31 respondents stated strongly agree, only one of them or $2.5 \%$ stated disagree to pay attention to what their children should eat and drink. Table 5.3 shows subscale of children's need of self-care such as bathing, defecation, urination, and menstruation. Those who stated strongly agree were $67.5 \%$ or 27 respondents, and agree were $32.5 \%$ or 13 respondents. In subscale of hugging and kissing the children with Down syndrome, there were $67.5 \%$ or 27 respondents stated strongly agree, $32.5 \%$ or 13 respondents stated agree. Approximately $87.5 \%$ of respondents stated strongly agree that they are happy when their children 
could speak a few words that are understandable by anyone. Approximately $21 \%$ of respondents stated agree to spend strength and time to take care of their children. Approximately $60 \%$ or 24 respondents stated agree to spend a lot of time to assist their children in learning (for example: speaking, writing, reading, etc) (Table 1).

There were $45 \%$ or 18 mothers of children with Down syndrome who stated agree to threaten their children with scary things when children are fussy, stubborn, disobedient, and very demanding, but there was also one of them or $2.5 \%$ stated disagree. Many respondents, approximately $60 \%$ or 24 of them stated disagree to ignore their children for a while when the children keep on fussy, stubborn, disobedient, and very demanding. Many mothers of children with Down syndrome stated agree, approximately $60 \%$ or 24 respondents, to yell loudly when the children keep crying and very stubborn. But there were $12.5 \%$ or 5 respondents stated disagree to yell loudly when the children keep crying and very stubborn. Many respondents, approximately $52.5 \%$ of them stated strongly agree to watch their children when going in public areas. Respondents who stated strongly agree to watch their children because they worry about things that could possibly harm the children were $50 \%$ or 20 respondents (Table 2 ).

There were $62.5 \%$ or 25 mothers of children with Down syndrome who often clean up their children's teeth, even there were $12.5 \%$ or 5 mothers of children with Down syndrome who never clean up their children's teeth. Mothers of children with Down syndrome who often assist their children to clean up the teeth were $57.5 \%$ or 23 respondents, but there were also $12.5 \%$ or 5 respondents who never assist their children to clean up the teeth. Mothers of children with Down syndrome who often watch their children cleaning up the teeth and mouth were $70 \%$ or 28 respondents, and also there were $10 \%$ or 4 respondents who never watch their children cleaning up the teeth and mouth. There were $62.5 \%$ or 25 mothers of children with Down syndrome who often clean up their children's teeth using toothbrush and toothpaste, even there were $10 \%$ or 4 respondents who never use toothbrush and toothpaste

Table 1. Frequency distribution of perceived maternal parenting responsiveness for children with down syndrome

\begin{tabular}{|c|c|c|c|c|c|c|c|c|}
\hline \multirow[t]{2}{*}{ Item } & \multicolumn{2}{|c|}{ Strongly agree } & \multicolumn{2}{|c|}{ Agree } & \multicolumn{2}{|c|}{ Disagree } & \multicolumn{2}{|c|}{$\begin{array}{l}\text { Strongly } \\
\text { disagree }\end{array}$} \\
\hline & $\mathrm{n}$ & $\%$ & $\mathrm{n}$ & $\%$ & $\mathrm{n}$ & $\%$ & $\mathrm{n}$ & $\%$ \\
\hline Reassuring my child when he/she is afraid & 29 & 72.5 & 10 & 25 & 1 & 2.5 & 0 & 0 \\
\hline Cheer up my child when he/she is sad & 30 & 75 & 9 & 22.5 & 1 & 2.5 & 0 & 0 \\
\hline Treating my child as friend & 28 & 70 & 10 & 25 & 2 & 5 & 0 & 0 \\
\hline Paying attention to what my child should eat and drink & 31 & 77.5 & 8 & 20 & 1 & 2.5 & 0 & 0 \\
\hline $\begin{array}{l}\text { Paying attention to self-care needs of my child such as } \\
\text { bathing, defecation, urination, menstruation }\end{array}$ & 27 & 67.5 & 13 & 32.5 & 0 & & 0 & 0 \\
\hline Hugging and kissing my child & 27 & 67.5 & 13 & 32.5 & 0 & 0 & 0 & 0 \\
\hline $\begin{array}{l}\text { Feeling happy when my child could speak a few words } \\
\text { that are understandable by anyone }\end{array}$ & 35 & 87.5 & 5 & 12.5 & 0 & 0 & 0 & 0 \\
\hline Spending strength and time to take care of my child & 18 & 45 & 21 & 52.5 & 0 & 0 & 1 & 2.5 \\
\hline $\begin{array}{l}\text { Spending a lot of time to assist my child in learning (for } \\
\text { example: speaking, writing, reading, etc) }\end{array}$ & 24 & 60 & 15 & 40 & 0 & 0 & 1 & 2.5 \\
\hline
\end{tabular}

Table 2. Frequency distribution of perceived maternal parenting demandingness for children with down syndrome

\begin{tabular}{|c|c|c|c|c|c|c|c|c|}
\hline \multirow[t]{2}{*}{ Item } & \multicolumn{2}{|c|}{ Strongly agree } & \multicolumn{2}{|c|}{ Agree } & \multicolumn{2}{|c|}{ Disagree } & \multicolumn{2}{|c|}{$\begin{array}{l}\text { Strongly } \\
\text { disagree }\end{array}$} \\
\hline & $\mathrm{n}$ & $\%$ & $\mathrm{n}$ & $\%$ & $\mathrm{n}$ & $\%$ & $\mathrm{n}$ & $\%$ \\
\hline $\begin{array}{l}\text { Threatening my child with scary things when he/she is } \\
\text { fussy, stubborn, disobedient, and very demanding }\end{array}$ & 13 & 32.5 & 18 & 45 & 8 & 20 & 1 & 2.5 \\
\hline $\begin{array}{l}\text { Ignoring for a while if he/she keeps on fussy, stubborn, } \\
\text { disobedient, very demanding }\end{array}$ & 3 & 7.5 & 11 & 27.5 & 24 & 60 & 2 & 5 \\
\hline $\begin{array}{l}\text { Yelling loudly when my child keep crying, and very } \\
\text { demanding }\end{array}$ & 10 & 25 & 24 & 60 & 5 & 12.5 & 1 & 2.5 \\
\hline Watching my child when he/she is in public areas & 21 & 52.5 & 19 & 47.5 & 0 & 0 & 0 & 0 \\
\hline $\begin{array}{l}\text { Watching my child because I worry about things that } \\
\text { could possibly harm him/her }\end{array}$ & 20 & 50 & 20 & 50 & 0 & 0 & 0 & 0 \\
\hline
\end{tabular}


Table 3. Frequency distribution of mother's behavior in maintaining dental health of children with down syndrome

\begin{tabular}{|c|c|c|c|c|c|c|c|c|}
\hline \multirow{2}{*}{ Item } & \multicolumn{2}{|c|}{ Very often } & \multicolumn{2}{|c|}{ Fairly often } & \multicolumn{2}{|c|}{ Sometimes } & \multicolumn{2}{|c|}{ Never } \\
\hline & $\mathrm{n}$ & $\%$ & $\mathrm{n}$ & $\%$ & $\mathrm{n}$ & $\%$ & $\mathrm{n}$ & $\%$ \\
\hline I clean up my child's teeth & 4 & 10 & 25 & 62.5 & 6 & 15 & 5 & 12.5 \\
\hline I assist my child to clean up his/her teeth & 5 & 12.5 & 23 & 57.5 & 7 & 17.5 & 5 & 12.5 \\
\hline $\begin{array}{l}\text { I watch my child when he/she clean up his/her teeth and } \\
\text { mouth }\end{array}$ & 6 & 15 & 28 & 70 & 2 & 5 & 4 & 10 \\
\hline $\begin{array}{l}\text { I clean up my child's teeth using toothbrush and } \\
\text { toothpaste }\end{array}$ & 10 & 25 & 25 & 62.5 & 1 & 2.5 & 4 & 10 \\
\hline I clean up my child's teeth twice daily & 7 & 17.5 & 22 & 55 & 6 & 15 & 5 & 12.5 \\
\hline $\begin{array}{l}\text { I clean up my child's teeth only at night before go to } \\
\text { bed }\end{array}$ & 2 & 5 & 8 & 20 & 12 & 30 & 18 & 45 \\
\hline $\begin{array}{l}\text { I clean up my child's teeth in the morning after } \\
\text { breakfast and at night before go to bed }\end{array}$ & 8 & 20 & 15 & 37.5 & 10 & 25 & 7 & 17.5 \\
\hline
\end{tabular}

Table 4. Description of results of mean score and standard deviation of mother's perception and behavior in maintaining dental health of children with down syndrome

\begin{tabular}{lccc}
\hline \multicolumn{1}{c}{ Variable } & $\mathrm{N}$ & Mean & $\begin{array}{c}\text { Standard } \\
\text { Deviation }\end{array}$ \\
\hline $\begin{array}{l}\text { Perceived parental } \\
\text { responsiveness }\end{array}$ & 40 & 33.00 & 2.99 \\
$\begin{array}{l}\text { Perceived parental } \\
\text { demandingness }\end{array}$ & 40 & 15.55 & 1.99 \\
\begin{tabular}{l} 
Behavior \\
\hline
\end{tabular} & 40 & 18.55 & 4.74 \\
\hline
\end{tabular}

Table 5. Correlation between perceived parenting style and mother's behavior in maintaining dental health of children with down syndrome

\begin{tabular}{ccc}
\hline \multirow{1}{c}{ Perception } & $\mathrm{N}$ & Behavior \\
\cline { 3 - 3 } & & $\mathrm{p}$ value \\
\hline Perceived parental responsiveness & 40 & $0.000^{* *}$ \\
Perceived parental demandingness & 40 & 0.642 \\
\hline
\end{tabular}

to clean up their children's teeth. In addition, there were $55 \%$ or 22 mothers of children with Down syndrome who often clean up their children's teeth twice daily. Tehre were $45 \%$ or 18 mothers of children with Down syndrome who never clean up their children's teeth at night before go to bed. Total of mothers of children with Down syndrome who often clean up their children's teeth in the morning after breakfast and at night before go to bed were 37.5\% or 15 respondents, and those who never were $17.5 \%$ or 7 respondents (Table 3 ).

Perceived maternal responsiveness in children with Down syndrome reached high score, as it approached the highest score of 36, with mean score of 33.00 and standard deviation of 2.99. Perceived maternal demandingness in children with Down syndrome reached high score, as it approached the highest score of 20 with the mean score of
15.55 and standard deviation of 1.99. Mother's behavior in maintaining dental health of children with Down syndrome showed low score, far from the highest score of 28 , with mean score of 18.55 and standard deviation of 4.74 (Table 4).

In addition, result of data analysis using multiple linear regression showed that there was strong correlation between perceived maternal parenting style and mother's behavior in maintaining dental health of children with Down syndrome $(\mathrm{R}=0.630, \mathrm{p}=0.000)$. Strong predictor that influence perceived maternal parenting style in children with Down syndrome and mother's behavior in maintaining dental health of children with Down syndrome was perceived maternal responsiveness.

\section{DISCUSSION}

Perceived parenting style defined as an opinion of children about styles of parental behaviors during their childhood. ${ }^{23,24}$ Perceived parenting style is related to parental behaviors that parents use to socialize their children. ${ }^{25}$ In this study we discuss about perceived maternal responsiveness and demandingness in children with Down syndrome in relation to mother's behavior in maintaining dental health of children with Down syndrome. According to the study result, there is strong correlation between perceived parenting style and mother's behavior in maintaining dental health of children with Down syndrome, wherein the strongest predictor is perceived parental responsiveness.

Parents with responsiveness style are those who always show affection, often smile, give appreciation, and encourage their children. ${ }^{13}$ Respondents always reassure when their children are afraid, cheer up their children when they are sad, treat them as friend, hug, kiss and pay attention to what their children should eat and drink. In addition, respondents strongly agree to pay attention to self-care of their children such as bathing, defecation, urination, and 
menstruation. The most challenging part in self-care of children with Down syndrome experienced by respondents is when their daughter get menstruation. Girls with Down syndrome could not use pads at all, they could only stare at blood stains on pants. ${ }^{19}$

Respondents strongly agree that they feel happy when children with Down syndrome could speak a few words that are understandable by anyone. Many mothers of children with Down syndrome feel very happy when their children could speak a few words that are understandable by anyone. ${ }^{26}$ In perceived maternal responsiveness of children with Down syndrome, total of mothers who agree to spend strength and time to take care of their children were approximately $21 \%$. In Korea, this is considered as family responsibility, which means that family is responsible for additional needs related to care for them. ${ }^{27}$ Korean mothers of children born with Down syndrome experienced any difficulties in caring for their children. ${ }^{27}$ Respondents agree to spend a lot of time to assist their children in learning (for example: speaking, writing, reading, etc). In a qualitative study, it had been found that there was a Chinese mother trying to increase learning potential of her child that born with Down syndrome, as her child experienced delay in learning. ${ }^{19}$

In addition to perceived maternal responsiveness style in children with Down syndrome, it was also found in respondents answers which still applied perceived parenting demandingness. Perceived parenting demandingness is a perception that describes standards set by parents are related to parental control of child's behavior. ${ }^{13}$

In the present study we found that many mothers of children with Down syndrome stated agree to yell loudly when their children keep crying and very stubborn. It is possible that when parents are more hostile, critical, irritable, and harsh, children do not feel like they are important or competent. ${ }^{28}$ Further, when parents express a dislike or aversion to their children, the parents might be less likely to be actively engaged in their children's development that lead to increased negative behavioral problems. Whereas in this study, mothers of children with Down syndrome were homemakers that should pay attention to their children's needs.

Although many mothers of children with Down syndrome stated agree to yell loudly when their children keep crying, very stubborn, but they keep watching and monitoring their children. It is shown by their answers which stated strongly agree to watch their children when going in public areas, as they worry about things that could possibly harm their children. Mothers of children with Down syndrome consider their children are susceptible to the danger, because there are barriers of social contact thus mothers try to watch their children intensively. ${ }^{29}$

Scoring for mother's behavior in maintaining dental health of children with Down syndrome in the present study appears low. This is due to many mothers of children with Down syndrome did not assist their children to clean up their teeth at night before go to bed. Whereas the optimal time to brush teeth is after breakfast and before go to bed. ${ }^{30}$ The reasons of someone apply health behavior or not are thoughts and feelings that reflect knowledge, perception, attitude, belief and assessment regarding health. ${ }^{31}$

In this term, perceived maternal parenting style of children with Down syndrome is crucial to influence mother's behavior in maintaining dental health of their children born with Down syndrome. Perceived parenting style is closely related to parental behavior in caring, raising, and educating children. ${ }^{32}$ Parenting comprises care practices used by parents of children up to three years old, as well as beliefs they hold and that guide their behavior. ${ }^{13}$ The more mothers engaged in good dental health-related behavior for themselves, the more likely they were to know more about promoting their children's oral health. ${ }^{33}$

It could be concluded that perceived maternal parenting style in children with Down syndrome that mostly applied is perceived parental responsiveness compared to demandingness. Perceived parental responsiveness applied by mothers of children with Down syndrome has shown correlation with mother's behavior in maintaining dental health of their children. The results of this study are expected to be a basis of development of promotive and preventive approach for dental health of children with Down syndrome, either by dentists or other dental health professionals.

\section{REFERENCES}

1. Galley, R. Medical management of the adult patient with Down syndrome. JAAPA 2005; 18(4): 45-6, 48, 51-2.

2. Mulia A, Kristi E. Fasilities of kids therapy Down syndrome in Surabaya. Jurnal eDIMENSI Arsitektur 2012; 1: 1-6.

3. Amaral Loureiro AC, Oliveira Costa F, Eustáquio da Costa J. The impact of periodontal disease on the quality of life of individuals with Down syndrome. Downs Syndr Res Pract 2007; 12(1): 50-4.

4. Shore S, Lightfoot T, Ansell P. Oral disease in children with Down syndrome: causes and prevention. Community Pract 2010; 83(2): 18-21.

5. Oredugba F. Oral health condition and treatment needs of a group of Nigerian individuals with Down syndrome. Down's syndrome. Research and Practice 2007; 12(1): 72-6.

6. Al Sarheed. Comparative study of oral health among trisomy 21 children living in Riyadh, Saudi Arabia: Part 2, gingival condition. The Saudi Dental Journal 2015; 27: 224-7.

7. Haliza T, Normastura AR, Azizah Y. Dental anomalies and oral hygiene status of Down syndrome children. International Journal of Public Health and Clinical Sciences 2015; 2(3): 33-41.

8. Al-Maweri S, Al-Sufyani G. Dental caries and treatment needs of Yemeni children with Down syndrome. Dent Res J (Isfahan) 2014; 11(6): 631-5.

9. Oliveira AC, Pordeus IA, Luz CL. Mothers' perceptions concerning oral health of children and adolescents with Down syndrome: a qualitative approach. European Journal of Paediatric Dentistry 2010; 11(1): 27-9.

10. Bracksley S, Dickson-Swift V, Anderson K, Gussy M. An exploration of mothers' perceptions about dental health. Journal of Theory and Practice of Dental Public Health 2013; 1(1): 9-14.

11. Lawson KL. Expectations of the parenting experience and willingness to consider selective termination for Down syndrome. Journal of Reproductive and Infant Psychology 2006; 24(Issue 1) 43-59. 
12. Choi H, Riper, MV. Maternal perceptions to open-ended questions about life with Down syndrome in Korea. The Qualitative Report 2016; 21(2): 288-98.

13. Pasquali L, Gouvea VV, Santos WS, Fonseca PN, Andrade JM, Lima TJS. Perceptions of parents questionnaire: evidence for a measure of parenting styles. Paidéia 2012; 22 (52): 155-64.

14. Mahoney FP. The relationship between parenting stress and maternal responsiveness among mothers of childreen with developmental problems. Dissertation. Mandel School of Applied Social Sciences. Case Western Reserve University. 2009.

15. Calik Var E, Kilic S, Kumandas H. Investigating opinions of mothers on different socioeconomic status in terms of perceived maternal styles. Eurasian Journal of Educational Research 2015; 61: 81-98.

16. Goleman D. Emotional intelligence ( $10^{\text {th }}$ anniversary re-issue edn.). New York: Bantam Books; 2006.

17. Stewart SM, Bond MH, Kennard BD, Ho LN, Zaman RM. Does the Chinese construct of guan export to the West? International Journal of Psychology 2002; 37(2): 74-82.

18. Smith LS, Ree M, Leonard H. Oral health and children with an intellectual disability: a focus group study of parent issues and perceptions. Journal of Disability and Oral Health 2010; 11(4) 171-7.

19. Chan KG, Lim KA, Ling HK. Care demands on mothers caring for a child with Down syndrome: Malaysian (Sarawak) mothers' perspectives. International Journal of Nursing Practice 2014; 1-10.

20. Chand S, Chand S, Dhanker K, Chaudhary A. Impact of mothers' oral hygiene knowledge and practice on oral hygiene status of their 12-year-old children: A cross-sectional study. Journal of Indian Association of Public Health Dentistry 2016; 12(4): 323-6.

21. Joosa E, Berthelsen D. Parenting a child with Down syndrome: a phenomenographic study. School of early childhood. Australia: Queensland University of Technology.Victoria Park Road; 2006. p. 49-54.
22. Arikunto S. Research procedure, a practical approach. Edition revision. Jakarta: Rineka Cipta; 2010.

23. Fonte BA. Relationship between parenting style, emotional intelligence and self esteem. 2009.

24. Lopes PN, Brackett MA, Nezlek JB, Schütz A, Sellin I, Salovey P. Emotional intelligence and social interaction. Personality and Social Psychology Bulletin 2004; 30(8): 1018-34

25. Kobarg APR, Vieira V, Vieira ML. Validação da escala de lembranças sobre práticas parentais (EMBU). Avaliação Psicológica 2010; 9(1): 77-85.

26. Choi H, Riper, MV. Maternal perceptions to open-ended questions about life with Down syndrome in Korea. The Qualitative Report 2016; 21(2): 288-98

27. Choi EK, Lee YJ, Yoo IY. Factors associated with emotional response of parents at the time of diagnosis of Down syndrome. Journal for Specialists in Pediatric Nursing 2011; 16(2): 113-20.

28. Phillip AB. A comparison of parenting dimensions between mothers of childreen with Down syndrome and mothers of typically developing children. Dissertation. Tuscaloosa: Department of Psychology in the Graduate School of the University of Alabama; 2016.

29. Lupton D, Schmied V. The right way of doing it all': First-time Australian mothers' decisions about paid employment. Women's Studies International Forum 2002; 25: 97-107.

30. Wong DL, Hockenberry M, Wilson D, Winkelstein ML, Schwartz P. Textbook of pediatric nursing. $6^{\text {th }}$ ed. Jakarta: EGC; 2009.

31. Budiharto. Introduction health behavior and dental health education. Jakarta: EGC; 2010.

32. Doinita NE, Maria ND. Attachment and parenting style. ProcediaSocial and Behavioral Sciences 2015; 203: 199-204.

33. Akpabio A, Klausner CP, Inglehart MR. Mothers'/guardians' knowledge about promoting children's oral health. Journal of Dental Hygiene 2008; 82(1): 8-9. 